\title{
Editorial
}

\section{Metabolic Syndrome: The Current Concept}

Razzak MA ${ }^{1}$, Rahman MM$^{2}$

DOI: https://doi.org/10.3329/jafmc.v14i2.45881

The metabolic syndrome (MetS) is a constellation of obesity, hyperglycaemia, decreased high density lipoprotein (HDL), increased triglyceride and high blood pressure ${ }^{1}$. The underlying causes of MetS include overweight and obesity, insulin resistance, an unhealthy dietary pattern, physical inactivity, genetic factors and aging ${ }^{2}$. The MetS, as a driver of current epidemics of diabetes and cardiovascular diseases (CVD), has become a major challenge to public health around the world. The association of MetS with myocardial infarction (MI), stroke and diabetes has been extensively documented and CVD is the major cause of death in the developing world ${ }^{3}$. The worldwide prevalence of MetS in the adult population is on the rise with an estimated prevalence of $20-25 \%{ }^{2}$. Adults with MetS are twice as likely to die from and are three times as likely to have a heart attack or stroke compared with people without the MetS. In addition, they have a five-fold greater risk of developing type 2 diabetes. In this backdrop, MetS is being considered as public health issue globally ${ }^{2-3}$.

Importantly, about $80 \%$ of the global burden of CVD related death occurs in low and middle-income countries ${ }^{4}$. The detection, prevention and treatment of the MetS components should become an important approach for the reduction of the cardiovascular and other disease burden in the general population ${ }^{5}$. Prevalence of non-communicable chronic diseases and associated mortality has also increased dramatically in Bangladesh in the last few decades. Bangladesh, a developing country with fast economic growth, has been experiencing rapid urbanization for the past several decades. This development and urbanization raises the concern that the chronic disease burden may show an increasing trend in future, especially due to altering food habit including increased access to and popularity of processed food, irregular meal times, less physical activity etc ${ }^{6-9}$.

A study held under BMC Public Health, Bangladesh revealed that low HDL cholesterol is the most frequent individual component of MetS in Bangladesh. High blood pressure has been seen as the second most prominent MetS component. High fasting glucose is the third most prevalent MetS component. The underlying factors behind the increased prevalence of low HDL, high blood pressure and high fasting glucose among Bangladeshi population could be multifarious. However, regional changes in disease patterns from communicable to non-communicable diseases, an increasing trend of urbanization and fascination for adopting western lifestyle could influence such high prevalence ${ }^{10,11}$. Rapid and unplanned urbanization is responsible for lifestyle change such as physical inactivity, changes in diet and stress and is closely linked with higher prevalence of MetS and is evidenced by the higher weighted pooled prevalence of MetS observed among urban population.

In Bangladesh, there is no population-based surveillance system to track non-communicable chronic disease. Also there is a lack of national population based surveys or central administrative health data to obtain accurate information on prevalence of disease like MetS. Having comprehensive information about the prevalence of MetS can be very effective for planning and executing preventive strategies for such diseases $^{12}$. Despite differences in diagnostic criteria, gender, age and geographic area of subjects studied, the prevalence of MetS is high and rising in Bangladesh according to this systematic review and recommends an urgent attention from both the clinical and public health viewpoint. Hence strategies aimed at primary prevention are required to mitigate a further increase in the prevalence and for the reduction of the morbidity and mortality associated with MetS. It is also extremely important to explore possible risk factors, especially those related to lifestyle which need to be addressed. Knowledge of these factors may be informative in the monitoring of MetS and could contribute to planning and prevention strategies to tackle this problem ${ }^{13}$.

In this edition of JAFMC, an original article and a review article on MetS have published, which extensively discusses the worldwide load of this condition and its various associations. This is an emerging threat which should be addressed soon rather than later for a healthy future generation.

\section{References}

1. Magliano DJ, Shaw JE, Zimmet PZ. How to best define the metabolic syndrome. Ann Med 2006; 38:34-41.

2. Alberti G, Zimmet P, Shaw J et al. The IDF consensus worldwide definition of the metabolic syndrome. International diabetes federation 2006:1-24.

3. Ezzati M, Hoorn SV, Lawes CM et al. Rethinking the "diseases of affluence" paradigm: global patterns of nutritional risks in relation to economic development. PLoS Med 2005; 2(5):e133.

1. Brig Gen Md Abdur Razzak, MBBS, MCPS, FCPS, APLAR Fellow in Rheumatology, Professor and Head, Department of Medicine, Armed Forces Medical College, Dhaka (E-mail: razzakprm@yahoo.com) 2. Maj Gen Md Mustafizur Rahman, MBBS, MPH, MBA, FCGP, Ex-Commandant, Armed Forces Medical College, Dhaka. 
4. Gaziano TA, Opie LH, Weinstein MC. Cardiovascular disease prevention with a multidrug regimen in the developing world: A costeffective analysis. Lancet 2006; 368 Z(9536):679-86.

5. Eckel RH, Grundy SM, Zimmet PZ. The metabolic syndrome. Lancet 2005; 365:1415-28.

6. Stern MP, Williams K, González-Villalpando C et al. Does the metabolic syndrome improve identification of individuals at risk of type 2 diabetes and/or cardiovascular disease? Diabetes Care 2004; 27:2676-81.

7. Eckel RH, Grundy SM, Zimmet PZ. The metabolic syndrome. Lancet 2005; 365:1415-28.

8. Hildrum BCB, Mykletun A, Hole T et al. Age-specific prevalence of the metabolic syndrome defined by the International Diabetes Federation and the National Cholesterol Education Program: The Norwegian HUNT 2 study. BMC Public Health 2007; 7:220.

9. Saquib N, Saquib J, Ahmed T et al. Cardiovascular diseases and Type 2 Diabetes in Bangladesh: A systematic review and meta- analysis of studies between 1995 and 2010. BMC Public Health 2012; 12:434.

10. Low WY, Lee YK, Samy AL. Non-communicable diseases in the Asia-Pacific region: Prevalence, risk factors and community-based prevention. Int J Occup Med Environ Health 2015; 28:20-6.

11. Misra A, Khurana L. The metabolic syndrome in south Asians: epidemiology, determinants, and prevention. Metab Syndr Relat Disord 2009;7:497-514.

12. Mainuddin A, Choudhury $K$, Ahmed $K$ et al. The metabolic syndrome: Comparison of newly proposed IDF, modified ATP III and WHO criteria and their agreements. Cardiovascular Journal 2013; 6:17-22.

13. Chowdhury MZI, Anik AM, Farhana Z, Bristi PD; Prevalence of metabolic syndrome in Bangladesh: A systematic review and metaanalysis of the studies: BMC Public Health 2018; 18:308. 